\title{
Japan Adult Moyamoya (JAM) Trial in 2002
}

\author{
JAM Trial Group
}

\section{Japan Adult Moyamoya (JAM) Trial in 2002}

JAM Trial Group

Summary: Recurrent bleedings have been known to aggravate the prognoses of patients who experienced cerebral bleeding attacks related to moyamoya disease. Hemodynamic stress on the moyamoya vessels enlarged as collateral pathways has been attributed to the bleeding episodes Bypass surgery has been performed for these patients to prevent recurrent attacks by reducing the hemodynamic stress on the moyamoya vessels. However, the preventive effect of bypass surgery against recurrent bleedings has not yet been statistically proven.

To establish the treatment guidlines for moyamoya disease with hemorrhagic onset, 20 Japanese centers have combined to evaluate the benefit of direct anastomotic bypass surgery such as superficial temporal artery to middle cerebral artery anastomosis in randomized patients who have experienced hemorrhagic episodes related to moyamoya disease and who have received either best medical treatment alone or best medical treatment plus extracranial-intracranial bypass surgery. This prospective randomized controlled trial named the Japan Adult Moyamoya (JAM) Trial was initiated in January 2001. Twenty patients have been already enrolled in this study.

\section{はじめに}

脳出血発作で発症したもやもや病では, 再出血が予後を 悪化させ致死率を上昇させる要因であることはよく知られ ている(6)79)10). バイパス手術を行い脳血流量が改善する と, もやもや血管にかかる血行力学的負荷が軽減し再出血 を予防できる可能性があると従来から考えられてきた。経 験の多いいくつかの施設やグループからこの可能性を示唆 する成績も報告されてきたが，過去に行われた全国的なア ンケート調査では必ずしも同様の結果ではない2)315)8)9). つまり，バイパス手術のもつ再出血予防効果について科学 的根拠に基づいて統計学的に証明した研究は存在しない.

このため，出血発症成人もやもや病に対する治療指針を 決定しバイパス手術の再出血予防効果を明らかにするた

\section{Key words:}

randomized controlled trial

- moyamoya disease

- bypass surgery

Surg Cereb Stroke (Jpn) 31: 13-17, 2003

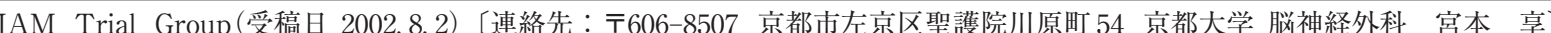
address: Susumu Miүamoto, M.D., Department of Neurosurgery, Kyoto University Graduate School of Medicine, 54 Shogoin, Kawahara-cho, Sakyo-ku, Kyoto City, Kyoto 606-8507, Japan

め，厚生労働省特定疾患対策研究事業の一環として Japan Adult Moyamoya (JAM) Trial) が2001年1月より開始し た ${ }^{4)}$. 本研究は, 多施設間共同研究により内科的治療群と, 内科的治療十バイパス手術群との無作為割付による比較検 討を行う prospective randomized controlled trial (RCT) である. study designについてはすでに公表したが，研究 開始後JAM trial全体会議を経て若干の protocol変更が行 われた。

本稿は第 31 回日本脳卒中の外科学会において公表され たJAM trialの study design と研究の進渉状況を報告する ものである.

\section{研究の対象}

脳出血，脳室内出血もしくはくも膜下出血の発作を 1 年 
以内に認めたもやもや病患者で，付随する水頭症などの続 発的病態に対する治療が終了後 1 力月以上経過し, 日常生 活レベルがほぼ自立している (modified Rankin disability scale $0 \sim 2) 16$ 歳以上 65 歳以下の症例を対象とした.

神経放射線学的に CT 上一血管支配領域にわたる広沉な 脳梗塞を認めず，脳梗塞があっても contrast enhancement 受けないこと，血管造影所見としては厚生労働省 診断基準の確実例に準拠することが必須で, 対象の均一性 を高めるために，いわゆる一側性もやもや病や類もやもや 病は除外した。また, ウイリス動脈輪の脳主幹動脈に脳動 脈瘤を合併するものも除外した。

これ以外の臨床的な exclusion criteria としては，1) modified Rankin disability scale 3 以上の重篤な神経症状, 2）動脈硬化性病変抢よび塞栓性病変による内頸動脈の閉 塞性病変があるもの，3）悪性腫瘍，心房細動その他塞栓 源となるような不整脈, 心不全, 肝不全, 腎不全, 呼吸不 全があるもの，4）6力月以内の心筋梗塞，および冠動脈 不全があるもの，5）出血時間や凝固時間の延長，6）空腹 時血糖值が $300 \mathrm{mg} / \mathrm{dl}$ 以上あるいはインスリン治療を要す る耐糖能低下があるもの，7）拡張期血圧 $110 \mathrm{mmHg}$ 以上 の高血圧症，8）過去に EC-IC bypass術を施行されている もの，8）妊娠中の症例などを除外項目とした。

\section{方法}

\section{1. 症例登録}

本研究の登録にあたっては，患者本人および家族に病 態・治療の現状について十分に説明し，書面による同意を 得るインフォームドコンセントが必須とされている. 神経 放射線学的および臨床的 inclusion criteriaへの適合につい て eligibility confirmationを行い, その後に症例が登録さ れ, 研究登録責任者によって乎術群・非手術群の無作為割 付がなされる。もやもや病ではその出血部位によりバイパ 又手術のもつ出血予防効果に違いがある可能性があるた め, 後大脳動脈只起始する穿通枝領域 (視床・側脳室三 角部など)に起こった出血症例を $\mathrm{P}$ 群とし, 内頸動脈終末 部・前㧍よび中大脳動脈近位部から起始する穿通枝領域 (レンズ核線条体・側脳室前角・側脳室体部など)に起こ った出血症例を A 群) と分類し, randomizationにあたっ ては A 群・P群の含まれる比率が手術群・非手術群の双 方でほほ同数になるよう stratified randomizationが行わ れている.

登録期間は 2001 年 1 月 1 日より 5 年間として, 手術群, 非手術群各 80 例, 合計 160 例を目標症例数とし, 登録か ら 5 年間の経過を追跡解析する。なお， 5 年間の追跡期間 が終了しても，原則的に本研究終了まで全症例を follow upする.

14 脳卒中の外科 $31 ： 2003$

\section{2. 治 療法}

手術群では術者を限定し登録後 3 力月以内に elective staged operation として原則として両側から左右別に行 い，この期間内の手術回数は問わないこととした。手術術 式の選択については各施設に委ねるが，少なくともその術 式の中に singleもしくは double STA-MCA anastomosis を行うこととし, 間接バイパスを付加することは可能であ るが，間接バイパスのみの術式や high flow bypassあるい は omental graftは認めないこととした.

薬物治療の内容としては, 出血発作以外に脎虚血症状を 併せて呈する症例など例外的な場合を除いて原則として抗 血小板製剂や抗凝固製剂は用いない.

\section{3. 追 跡}

各施設で内科と外科がペアを組み経過を追跡観察し，神 経症候, CT/MRI, 脳血流測定, 脳血管造影などの検查項 目を追跡し，CT/MRI，脳血管造影，脳循環などの評価に 関しては適宜, 画像診断委員会を設けて評価される。

\section{End point}

再発予防に関する primary end pointは再出血発作, 脳 虚血発作による completed stroke，その他の原因による死 亡あるいは severe disability (modified Rankin disability scale $3,4,5)$ となったもの，拈よび内科医の判断でバイパ ス手術に移行したもの (progressing stroke, crescendo TIA ど)を bad outcome として, 各時期において乎術群 と非手術群との間で比較検討する.

再出血予防に関する secondary end pointは, 再出血発 作およびそれによる死亡あるいは severe disability (modified Rankin disability scale 3,4,5)である。これら の episodeをbad outcomeとして, 各群におけるその比率 を比較評価する。

\section{5. 研究の中止, 変更}

中間解析の結果で，一方の群が有意に勝ることが明らか になった場合，あるいはその他必要が生じた場合には安全 監視委員会に検討を依頼して研究の中止あるいは適切な変 更を行う。

\section{JAM (supplement) trial および non-randomized data} base について

JAM trial は modified Rankin disability scale $0 \sim 2$ の みを対象としているため, 万一重篤な出血発症例がより高 い頻度で再出血発作をきたす場合にはこれを反映しなくな る.このような preallocation biasを少しでも少なくする ために, 2002 年 7 月より副次研究である JAM (supple- 
ment) trial と exclusion 症例についての non-randomized data base登録が開始されている.JAM (supplement) trial は modified Rankin disability scale 3 のみを対象とし た prospective RCTであり，再出血発作その他の原因に よる死亡を end pointとする以外はJAM trial と同様の study designである.

\section{7. 研究組織 (Table 1)}

8. 進渉状況

Table 1 に示した合計 22 施設において症例登録が行われ
ており，2002年 8 月 5 日現在 20 例の登録があり，手術群 11 例・非手術群 9 例に割り付けられている。 これまで end point に達した症例はない。

\section{考察}

出血発症もやもや病に対する治療指針を明らかにするた めには，バイパス手術の持つ再出血予防効果を統計学的に 検討する RCT が必要である。これまで統計学的な解明が なされなかった原因は，1）サンプルサイズが小さいため 症例集約が難しい，2）再出血率が不明である，3）出血発

Table 1

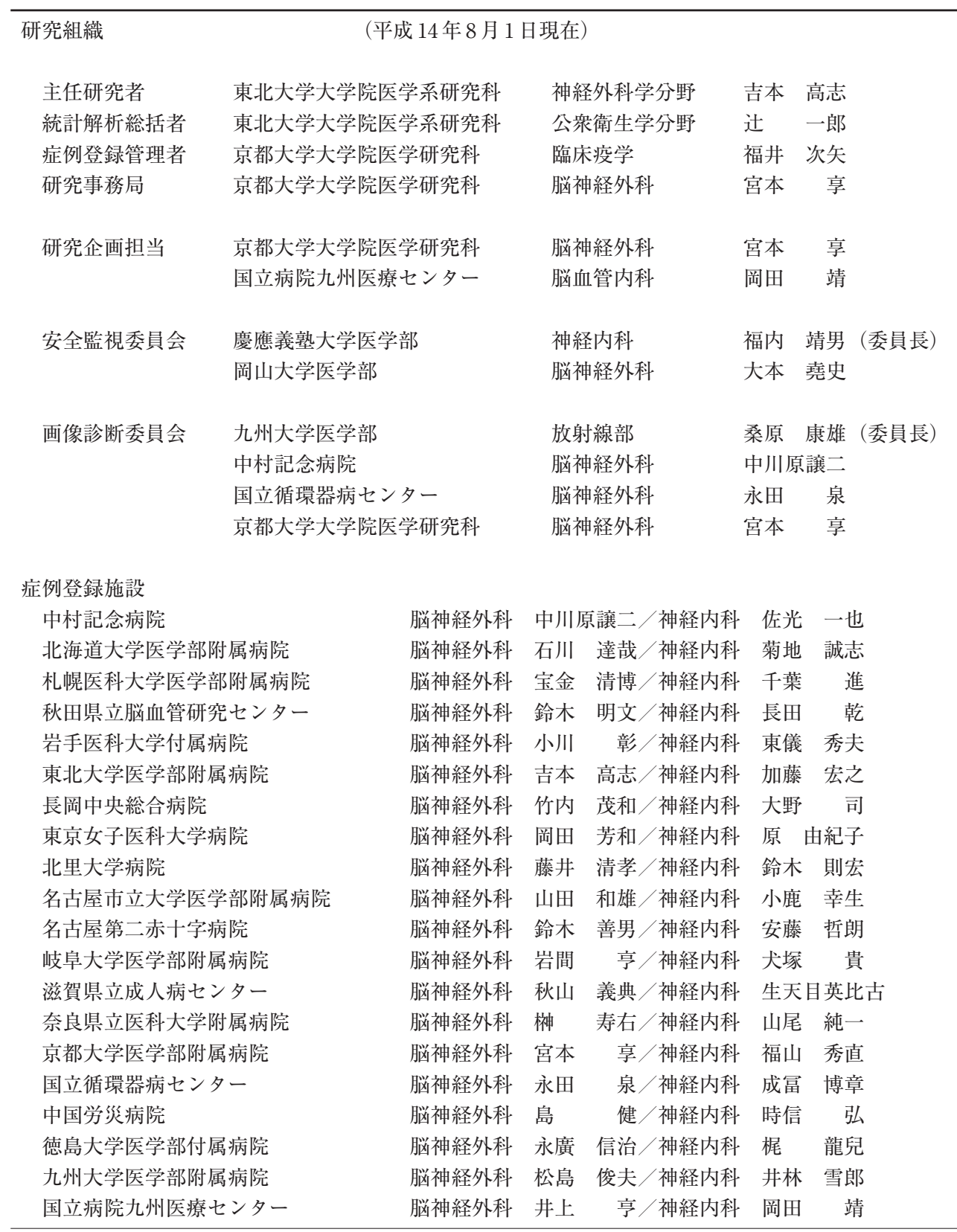


症もやもや病の多様な病態，4）外科治療法の多様性など の問題点が存在したためである。

まずサンプルサイズについては本研究開始前の試算では 出血例の年間発生率は 0.05 人 $/ 10$ 万人, 日本全体で年間 60 人程度の発生と試算された ${ }^{4)}$. 2001 年 1 月〜 12 月の間に はこの約半数に相当する 29 例が JAM trial 症例登録施設 に打いて受療した。このうちJAM trialに登録されたのは さらにこの約半数の 15 例である。登録されなかった理由 は年齢による exclusion 4 例・ modified Rankin disability scale 3 以上の重症 4 例 - 患者不同意 2 例・登録準備中 2 例・JAM trial参加前 2 例であった。この結果から JAM (supplement) trial と non-randomized data base 登録が開 始されたが，広報活動を行い症例集約を行うことは本研究 において非常に重要な問題と考えられる。

病態あるいは多様な手術術式に関する方針の不均一性と いう問題点を解決するために, JAM trialでは脳主幹動脈 の脳動脈瘤による合併・一側性病変や類もやもや病を除外 し，出血部位による stratified randomizationを行う study design となっている.また術式については必ず直接バイ パスである STA-MCA anastomosisを含みその術者を限定 することが規定されている.

本症の再出血率については過去の文献では，バイパス手 術を受けた症例では 10-20\%，非手術例では 30-40\% の再 出血率を報告しているものが多いが, 追跡期間や症状など 不詳な点が多い．福内らは厚生労働省研究班掠よびその関 連施設を対象とした研究班調查票全国集計を基に，これに これまで登録された出血発症例に対してアンケート調査を 行い, 出血発症 229 症例について治療法による予後の相違 を retrospective に検討した ${ }^{1)}$.この結果，保存的治療群 と比較して手術群とくに直接バイパスを行った群において 有意に累積生存率が高く, 再出血死の累積発生が有意に低 いことが判明しており，直接バイパスを必須とする prospective RCTであるJAM trial に対する期待は大きい ものと考えられる。

追跡期間の長さは解決されていない問題点である．従来 5 年以内に再出血が起こるのは再出血例の $60 \%$ とされてき たが，福内らの上記報告では 5 年後には両群間に差がみら れ，さらに 7 年後にはその差が拡大するようである。 JAM trialでは追跡期間を 5 年と設定している。症例集積 期間を含めると 10 年以上の study になり, 脱落症例 protocol 違反 ・担当医師の移動・data 蓄積などの問題を 考えると study に伴う困難は小さくないが, evidenceに 基づく治療指針作成のため本研究の成果が期待される.

\section{お 願 い}

もやもや病の病態や治療が本邦で解明されてきた歴史を
振り返れば，RCTの結果がバイパス手術にとって positive/negativeのいずれであれ，出血発症もやもや病に対 してなんらかの治療指針を打ち出すことはわれわれ日本の 脳神経外科医の責務であると考えます。

上記のように出血発症もやもや病は発生率の少ない疾患 であり，精度の高いRCTのためには症例の集約が keyで あると思われます。

日本脳卒中の外科学会の会員の皆様におかれましては, 出身大学その他の関連あるいは各施設における地域事情な どもあると存じますが，どうか出血発症もやもや病症例を 症例登録施設にご紹介いただきますようお願い申し上げま す.

また，本研究にご質問やご連絡の際は下記までお願い申 し上げます。

\section{JAM trial研究事務局}

宮本 享，山田圭介，菊田健一郎，高木康志

于 606-8507 京都市左京区聖護院川原町 54 京都大学脳神経外科内

TEL 075-751-3459 FAX 075-752-9501

E-mail:moya@kuhp.kyoto-u.ac.jp

\section{文献}

1）福内靖男，野川茂，山口㤵二（ほか：2001年度ウイリス 動脈輪閉塞症調查票全国集計. 厚生科学研究研究費補助金特 定疾患対策研究事業ウイリス動脈輪閉塞症の病因・病態に 関する研究 平成 13 年度総括・分担研究報告書, 2002 pp7-10

2) Fujii K, Ikezaki K, Irikura K, et al: The efficacy of bypas surgery for the patients with hemorrhagic moyamoya disease. Clin Neurol Neurosurg 99: 194-195, 1997

3) Houkin K, Kamiyama H, Abe $\mathrm{H}$, et al: Surgical therapy for adult Moyamoya disease. Can surgical revascularization prevent the recurrence of intracranial hemorrhage? Stroke 27: 1342-1346, 1996

4） JAM trial group: 出血発症成人もやもや病の治療指針に関 する研究—Japan Adult Moyamoya (JAM) Trial一. 脳卒 中の外科 30: $23-27,2002$

5) Kawaguchi S, Okuno S, Sakaki $\mathrm{T}$, et al: Effect of direct arterial bypass on the prevention of future stroke in patients with the hemorrhagic variety of moyamoya disease. J Neurosurg 93: 397-401, 2000

6) Kobayashi E, Saeki N, Oishi H, et al: Long-term natura history of hemorrhagic moyamoya disease in 42 patients. J Neurosurg 93: 976-980, 2000

7）盛岡基浩，濱田潤一郎，甲斐 豊，ほか：能本県下におけ るモヤモヤ病患者の長期追跡調查. 厚生省特定疾患ウイリ 又動脈輪閉塞症調查研究班 平成 12 年度研究報告書, 2001 pp11-14

8）辻一郎：出血型モヤモヤ病に対する血行再建術の再出血 予防効果に関する研究. 厚生省特定疾患ウイリス動脈輪閉 塞症調查研究班 平成 11 年度研究報告書, $2000, p p 40-42$

9) Yoshida Y, Yoshimoto T, Shirane R, et al: Clinical course, surgical management, and long-term outcome of 
moyamoya patients with regleeding after an episode of intracerebral hemorrhage: an extensive follow-up study. Stroke 30: 2272-2276, 1999

10）吉本高志, 吉田康子, 白根礼造：宮城県に扔ける出血発症
モヤモヤ病患者の長期追跡報告. 厚生省特定疾患ウイリス 動脈輪閉塞症調査研究班 平成 11 年度研究報告書, 2000 pp20-25 